\title{
The Position of Proximal Reference Point of Tibia Plateau for Correct Tibial Osteotomy in Total Knee Replacement: Prospective Randomized and 6 Years Follow-up Study
}

\author{
Kye Young Han, MD and Woo Young Chae, MD \\ Department of Orthopaedic Surgery, Kangwon National University College of Medicine, Chuncheon, Korea
}

\begin{abstract}
Purpose: When there is a varus deformity in proximal tibia, the extension of a tibial shaft axis tends to pass through the lateral intercondylar eminence. A prospective randomized study was conducted to find out whether the lateral eminence of tibia could serve as a reference point for proximal tibial osteotomy during total knee arthroplasty and results from 6-years follow up period were reported.

Materials and Methods: Forty-six patients (50 knees) who received total knee replacement arthroplasty from April to December 2004, were randomly divided into two groups. For a proximal tibial osteotomy, the proximal tibial reference point was located at the center of intercondylar eminence for group I and at the lateral eminence for group II and subsequently, the results were evaluated. Radiologic indices were the angles between the axis of the prosthesis and the mechanical/shaft axes of tibia and angle of the prosthesis in sagittal plane. Clinical indices were pain and function score of American knee society, functional score of Hospital for Special Surgery and range of knee joint motion.

Results: The angles between the axis of the prostheses and the mechanical/shaft axes of tibia were varus $1.64^{\circ} / 2.12^{\circ}$ in group I and valgus $0.57^{\circ} / 0.38^{\circ}$ in group II ( $\mathrm{p}=0.589 / \mathrm{p}=0.558)$. There were 6 cases of outliers $(27.2 \%)$ in group 1 and 3 cases $(15.0 \%)$ in group 2 . There was a significant difference in the pain score between group I (82.9) and II (91.4) ( $\mathrm{p}=0.032)$, respectively.

Conclusions: By moving the reference point of proximal tibial osteotomy laterally, lower incidence of outlier and residual varus deformity could be achieved.
\end{abstract}

Key words: Tibia, Lateral intercondylar eminence, Varus, Total knee arthroplasty, Tibial osteotomy.

\section{Introduction}

Proper implant insertion and alignment are important factors for good clinical results and long-term survival of total knee arthroplasty (TKA). To obtain correct alignment of tibial component,

Received May 3, 2011; Revised (1st) June 23, 2011; (2nd) July 26, 2011; Accepted August 2, 2011.

Correspondence to: Kye Young Han, MD.

Department of Orthopedic Surgery, Kangwon National University

Hospital, 17-1 Hyoja 3-dong, Chuncheon 200-947, Korea.

Tel: +82-33-258-2308, Fax: +82-33-244-2205

Email: hkyljh@kangwon.ac.kr

This is an Open Access article distributed under the terms of the Creative Common Attribution Non-Commercial License (http://creativecommons.org/licenses/by-nc/3.0/) which permits unrestricted non-commercial use, distribution, and reproduction in any medium, provided the original work is properly cited.

Copyright $\odot$ 2011. KOREAN KNEE SOCIETY

www.jksrr.org a tibial osteotomy has to be made perpendicular to the tibial axis or within $3^{\circ}$ in either varus or valgus alignment ${ }^{1,2)}$. In reality, however, a normal tibial osteotomy often results in a varus cutting. Han et al. ${ }^{3)}$ reported that an axis drawn from the center of the tibial plateau was not identical to the anatomical axis of the tibia in knock knees, resulting in a varus osteotomy. Cho ${ }^{4)}$ suggested that the point where the tibial axis and the articular surface meet should be used as a reference point in knees with varus deformity to avoid varus osteotomy.

In this study, we investigated whether the lateral intercondylar eminence can be used as a reference for proximal tibial osteotomy during TKA based on the fact that an extension of the tibial shaft axis that extends from the proximal $1 / 3$ rd to the distal $1 / 3 \mathrm{rd}$ at the center of the tibia tends to pass through the eminence. Our hypothesis was that radiological and clinical results of TKA would be more satisfying in the experimental group where the lateral eminence was used as a reference for tibial osteotomy compared to that in the control group where the center of the 
intercondylar eminence was used as a reference. This study is a prospective and randomized study with 6 years of follow-up.

\section{Materials and Methods}

Forty-six patients (50 knees) who underwent TKA from April to December in 2004, were randomly divided into two groups. Informed consent was obtained from all the patients before surgery. For proximal tibial osteotomy, an extramedullary tibial cutting guide was centered over the intercondylar eminence in group I and the lateral eminence in group II (Figs. 1, 2). At the ankle, the guide was placed over the center of the talus 3 to 5 $\mathrm{mm}$ medial to the midpoint of the ankle. In group I, there were 21 females ( 23 cases) and 2 males with a mean age of 72.2 years and 23 cases of osteoarthritis and 2 cases of rheumatoid arthritis. In group II, there were 20 females ( 22 cases) and 3 males with a mean age of 71.1 years and 22 cases of osteoarthritis, 2 cases of rheumatoid arthritis, and 1 case of osteonecrosis (Table 1). In group I, the prosthesis used was PFC-sigma (Depuy, Warsaw, IN, USA) in 18 cases and Scorpio (Osteonics, Allendale, NJ, USA) in 7 cases. In group II, PFC-sigma was used in 17 cases and Scorpio in 8 cases. The surgery was performed by the same surgeon in all the cases.

For clinical assessment, the pre- and postoperative pain and function score of the American knee society, functional score of the Hospital for Special Surgery (HSS), and range of joint motion were measured and compared between the groups. For radiological assessment, the angles between the axis
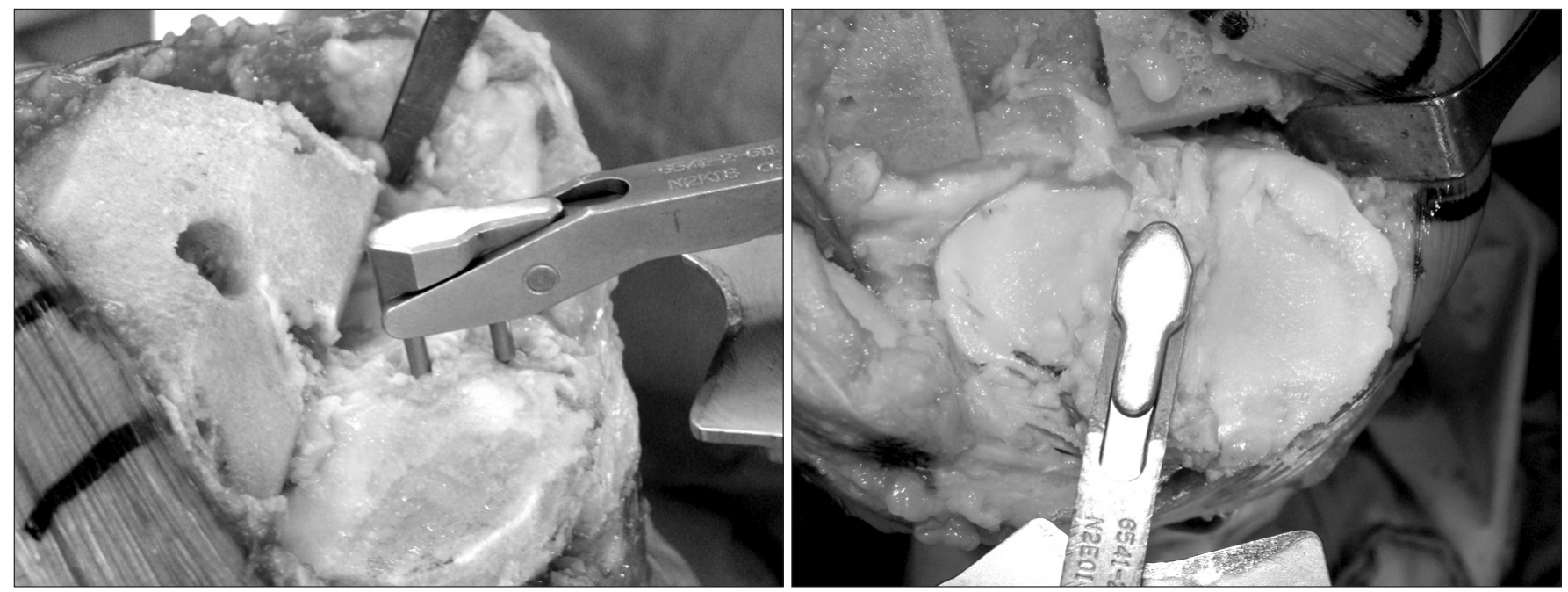

Fig. 1. The proximal reference point of group I was located at the center of intercon-dylar eminence.
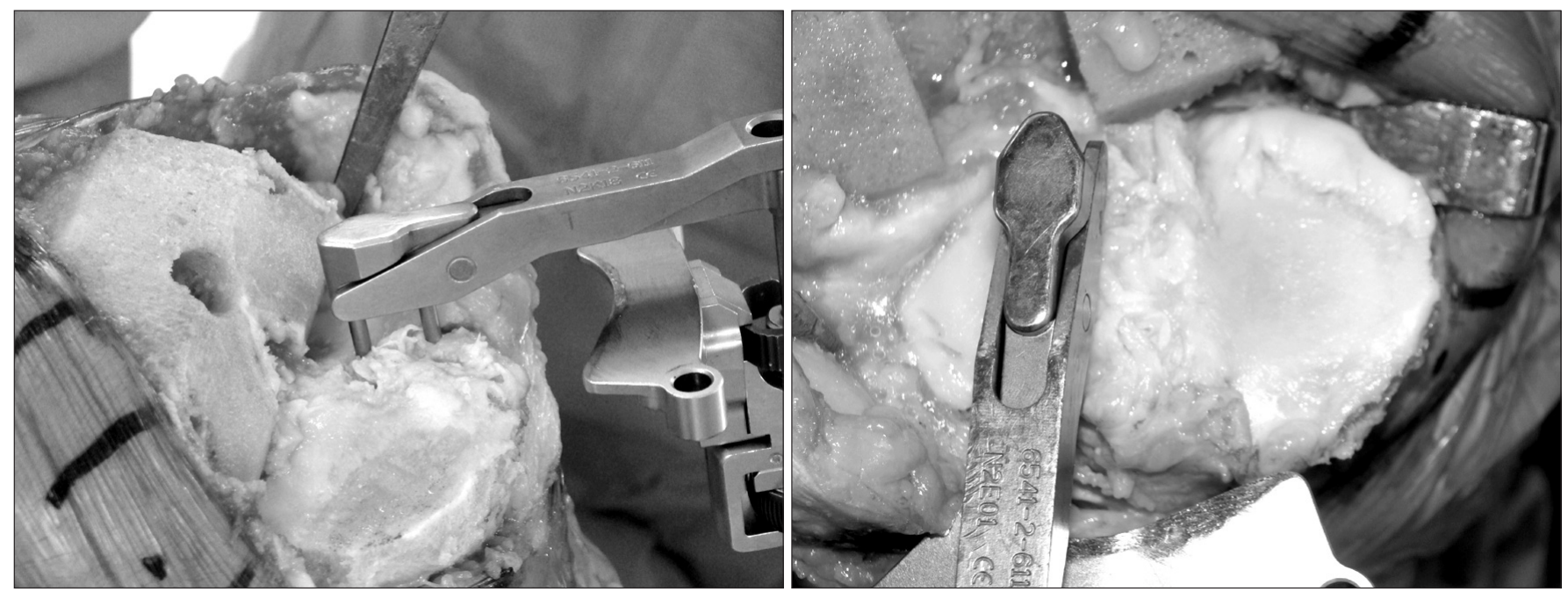

Fig. 2. The proximal reference point of group II was located at the lateral intercondylar eminence. 
Table 1. Demographic Characteristics of Subject Groups

\begin{tabular}{|c|c|c|c|}
\hline & Group 1 ( 22 cases) & Group 2 (20 cases) & p-value \\
\hline Age (y) & $72.0 \pm 0.7(59-84)$ & $73.9 \pm 0.6(59-82)$ & 0.603 \\
\hline Pain score ${ }^{a)}$ & $49.6 \pm 14.8(3-89)$ & $50.3 \pm 23.3(8-89)$ & 0.172 \\
\hline Function score $\mathrm{e}^{\mathrm{a})}$ & $35.1 \pm 7.0(-10-70)$ & $37.0 \pm 3.5(0-60)$ & 0.092 \\
\hline HSS & $62.9 \pm 10.6(31-84)$ & $60.8 \pm 25.5(36-80)$ & 0.437 \\
\hline Alignment of knee & varus $10.1^{\circ} \pm 1.2^{\circ}\left(\right.$ varus $21.4^{\circ}$-valgus $\left.8.2^{\circ}\right)$ & varus $8.95^{\circ} \pm 2.5^{\circ}\left(\right.$ varus $17.2^{\circ}$-valgus $\left.5.3^{\circ}\right)$ & 0.131 \\
\hline Range of motion & $94.1^{\circ} \pm 16.0^{\circ}\left(70^{\circ}-140^{\circ}\right)$ & $90.8^{\circ} \pm 8.3^{\circ}\left(80^{\circ}-140^{\circ}\right)$ & 0.524 \\
\hline
\end{tabular}

HSS: Hospital for Special Surgery.

${ }^{a}$ American Knee Society Score.

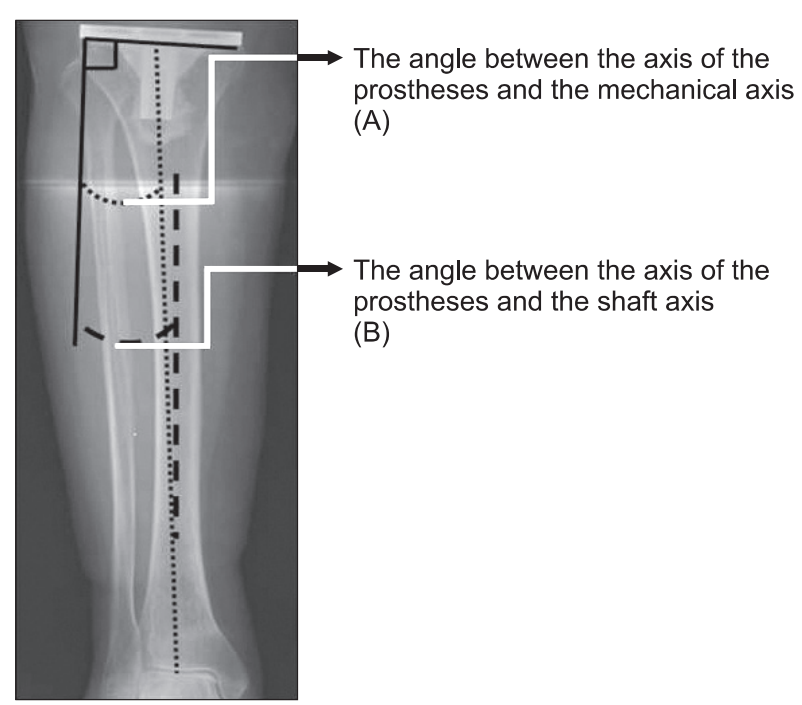

Fig. 3. The angles between the axis of the prostheses and the mechanical (A)/shaft (B) axes.

perpendicular to the tibial prosthesis and the mechanical/shaft axes of the tibia were measured on the full-length anteroposterior radiographs after surgery (Fig. 3). The radiographs were taken with the knee in full extension and the patella centered between the femoral condyles facing forward under full weight bearing. The mechanical axis was defined as a line between the center of the femoral head and the center of the ankle on the fulllength anteroposterior radiographs. The tibial component angle in sagittal plane ( $\delta$ angle) was measured according to the American Knee Society's radiographic evaluation system. Three of the authors measured angle using the PACS PiView Star (ver. 5.0, INFINITT, Seoul, Korea) excluding one of them who performed the surgery thrice. The median value was used for analysis. The sample size was calculated using G-power (sample size, 42; level of significance, 0.05; effect size, 0.8; and power, 0.80 ) and an independent sample $t$-test (SPSS ver. 12.0, SPSS Inc., Chicago, IL, USA) was used for statistical analysis.
Inter- and intraobserver agreement was assessed using both, the interclass correlation coefficient and the intraclass correlation coefficient. At 6 years after surgery, 42 cases excluding 8 that were lost to follow-up due to death or nonresponse were available for postoperative assessments. Clinical and radiological assessments were performed at the follow-up visit in 36 cases $(20$ cases in group I and 16 cases in group II), whereas clinical assessment was performed in only 6 cases ( 2 cases in group I and 4 cases in group II) via telephone interview.

\section{Results}

The mean angles between the axis perpendicular to the prosthesis and the mechanical/shaft axes of the tibia were not significantly different between the groups with $1.64^{\circ} \pm 3.2^{\circ}$ of varus (range, $2.96^{\circ}$ varus to $3.83^{\circ}$ valgus) and $2.12^{\circ} \pm 4.1^{\circ}$ of varus (range, $5.11^{\circ}$ varus to $3.23^{\circ}$ valgus) in group I and $0.57^{\circ} \pm 0.6^{\circ}$ of valgus (range, $1.49^{\circ}$ varus to $2.21^{\circ}$ valgus) and $0.38^{\circ} \pm 2.2^{\circ}$ of valgus (range, $4.79^{\circ}$ varus to $4.10^{\circ}$ valgus) in group II ( $\left.\mathrm{p}=0.589,0.558\right)$. The mean sagittal tibial component angle ( $\delta$ angle) was $85.1^{\circ} \pm 4.8^{\circ}$ (range, $83.1^{\circ}$ to $88.0^{\circ}$ ) in group I and $86.9^{\circ} \pm 11.3^{\circ}$ (range, $81.5^{\circ}$ to $\left.87.6^{\circ}\right)$ in group II $(\mathrm{p}=0.509)$ (Table 2$)$. The interclass correlation coefficient of the angles with the mechanical/shaft axes of the tibia was 0.92 and 0.89 , respectively. The intraclass correlation coefficient was high: 0.85 and 0.91 for the 1st examiner, 0.91 and 0.94 for the 2nd examiner, and 0.88 and 0.94 for the 3rd examiner. There were 6 cases of outliers (more than $3^{\circ}$ of varus or valgus) relative to the mechanical axis of the tibia $(27.2 \%$, varus in 5 cases and valgus in 1 case) in group I and 3 cases (15.0\%, varus in 2 cases and valgus in 1 case) in group II. The preoperative alignment of the 6 cases in group I was $17.0^{\circ}$ varus, $5.5^{\circ}$ valgus, $9.3^{\circ}$ varus, $11.6^{\circ}$ varus, $2.9^{\circ}$ varus, and $13.5^{\circ}$ varus, respectively, and the value of the 3 cases in group II was $4.8^{\circ}$ varus, $15.8^{\circ}$ varus, and $0.7^{\circ}$ varus, respectively. Loosening and subsidence of the tibial component were observed in a single case in group I (Fig. 4). 
Table 2. Comparison of the Radiographic Results

\begin{tabular}{|c|c|c|c|}
\hline & Group 1 & Group 2 & p-value \\
\hline $\begin{array}{l}\text { Alignment of tibia prosthesis based on } \\
\text { mechanical axis }\end{array}$ & Varus $1.64^{\circ} \pm 3.2^{\circ}$ (varus $2.96^{\circ}$-valgus $3.83^{\circ}$ ) & Valgus $0.57^{\circ} \pm 0.6^{\circ}\left(\right.$ varus $1.49^{\circ}$-valgus $\left.2.21^{\circ}\right)$ & 0.589 \\
\hline Alignment of tibia prosthesis based on shaft axis & Varus $2.12^{\circ} \pm 4.1^{\circ}\left(\right.$ varus $5.11^{\circ}$-valgus $3.23^{\circ}$ ) & Valgus $0.38^{\circ} \pm 2.2^{\circ}\left(\right.$ varus $4.79^{\circ}$-valgus $\left.4.10^{\circ}\right)$ & 0.558 \\
\hline$\delta$ angle $^{\text {a) }}$ & $85.1^{\circ} \pm 4.8^{\circ}\left(83.1^{\circ}-88.0^{\circ}\right)$ & $86.9^{\circ} \pm 11.3^{\circ}\left(81.5^{\circ}-87.6^{\circ}\right)$ & 0.509 \\
\hline
\end{tabular}

${ }^{a}$ Knee Society radiographic evaluation system.

Table 3. Comparison of the Clinical Results

\begin{tabular}{lcrc}
\hline & Group 1 & Group 2 & p-value \\
\hline Pain score $^{\mathrm{a})}$ & $82.9 \pm 4.7$ (range, 52-92) & $91.4 \pm 9.1$ (range, 82-100) & 0.032 \\
Function score $^{\mathrm{a})}$ & $77.8 \pm 10.6$ (range, 55-100) & $83.7 \pm 21.2($ range, 60-100) & 0.655 \\
HSS & $89.0 \pm 5.1$ (range, 73-100) & $90.5 \pm 9.8($ range, 73-100) & 0.598 \\
Range of motion & $117.3^{\circ} \pm 24.7^{\circ}\left(\right.$ range, $\left.105^{\circ}-145^{\circ}\right)$ & $112.8^{\circ} \pm 10.8^{\circ}\left(\right.$ range, $\left.100^{\circ}-140^{\circ}\right)$ & 0.137 \\
\hline
\end{tabular}

HSS: Hospital for Special Surgery.

${ }^{a)}$ American Knee Society score.
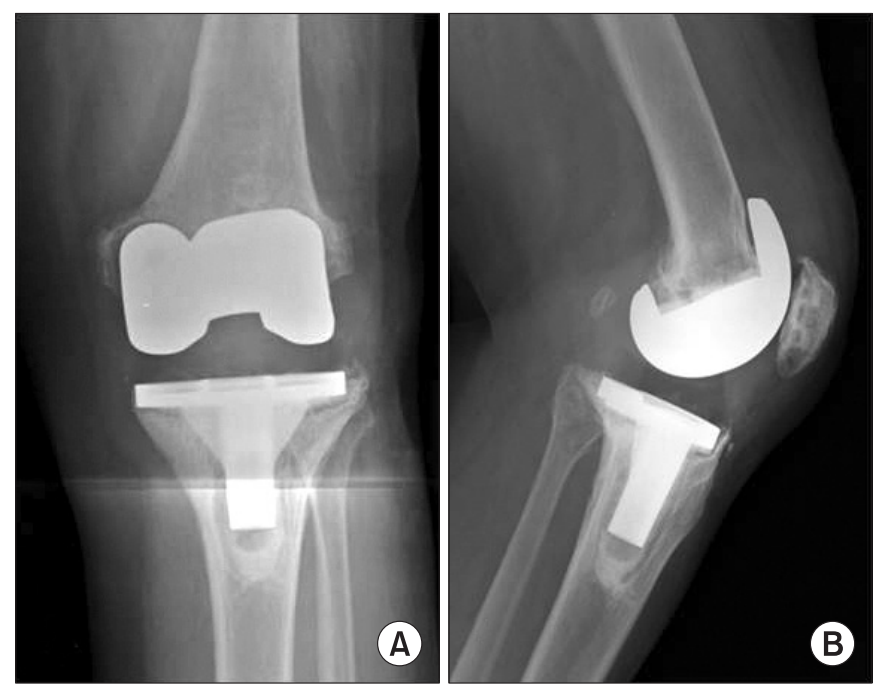

Fig. 4. Postoperative 5 years anteroposterior (A) and lateral (B) radiographs of sixty eight female patients showing sinking of tibial component and osteolysis around tibial prosthesis.

In case of the clinical assessment, the pain score was significantly higher in group I with $91.4 \pm 9.1$ points (range, 82 to 100 points) when compared to $82.9 \pm 4.7$ points (range, 52 to 92 points) in group II ( $\mathrm{p}=0.032$ ). Regarding the functional score, no significant difference was observed between the groups with $77.8 \pm 10.6$ points (range, 55 to 100 points) in group I and $83.7 \pm 21.2$ points (range, 60 to 100 points) in group II ( $\mathrm{p}=0.655)$. The HHS functional score was not significantly different between the groups with $89.0 \pm 5.1$ points (range, 73 to 100 points) in group I and $90.5 \pm 9.8$ points (range, 73 to 100 points) in group II ( $\mathrm{p}=0.598)$. There was no statistically significant difference in the range of motion with $94.1^{\circ} \pm 16.0^{\circ}$ (range, $70^{\circ}$ to $140^{\circ}$ ) preoperatively and $117.3^{\circ} \pm 24.7^{\circ}$ (range, $105^{\circ}$ to $145^{\circ}$ ) postoperatively in group I and $90.8^{\circ} \pm 8.3^{\circ}$ (range, $80^{\circ}$ to $140^{\circ}$ ) preoperatively and $112.8^{\circ} \pm 10.8^{\circ}$ (range, $100^{\circ}$ to $140^{\circ}$ ) postoperatively in group II ( $\mathrm{p}=0.137$ ) (Table 3 ).

\section{Discussion}

Most of the Korean patients who are candidates for TKA have genu valgum deformity, especially medial curvature of the proximal tibia combined with deformity of proximal tibial varus. In such cases, positioning the proximal center of an extramedullary guide at the center of the intercondylar eminence is likely to result in a varus osteotomy. In our present study, after confirming the safety and efficacy of the method used in the cadaver study of Nam et al. ${ }^{5}$ we carried out more valgus tibial osteotomy compared to the conventional methods by moving the center of the tibial osteotomy to the lateral eminence of the tibia that was in the extension of the tibial shaft axis and were able to obtain more stable alignment without damaging the mechanical axis.

In case of the radiographic assessment performed at the 6th postoperative year, the angles between the perpendicular line to the prosthesis and the mechanical/shaft axes were within the range of normal varus osteotomy in group I and close to $0^{\circ}$ in group II, although the differences between the groups were not statistically significant. The incidence of outliers was lower in group II. Although no significant difference could be observed 
due to the small sample size, the presence of varus deformity after surgery was lower and the alignment was better maintained in group II.

With respect to clinical assessment, no significant difference was found between the groups regarding 3 of the 4 indices. The pain score was higher in group II. We attributed this to the significantly lower than average scores of the 2 cases in group I: one with tibial implant subsidence due to loosening and the other with poor systemic condition.

Postoperative component alignment has been known as a crucial factor in the clinical results and longevity of TKA ${ }^{1,2,6,7)}$. Correction of deformity and knee alignment is especially important in cases of knees with varus deformity. Unfortunately, severe pre-operative deformity has been associated with postoperative malalignment ${ }^{8,9)}$. Lotke and Ecker ${ }^{10)}$ reported that proper knee alignment after TKA was $3^{\circ}-7^{\circ}$ of valgus relative to the tibiofemoral angle and Teeny et al. ${ }^{11)}$ reported that alignment between $3^{\circ}$ of varus and $3^{\circ}$ of valgus relative to the mechanical axis was acceptable. Varus tibial component positioning after varus osteotomy leads to an increase in stress in the medial side of the knee, which may eventually result in early failure of $\mathrm{TKA}^{12,13)}$.

An attempt to avoid varus osteotomy may result in excessive valgus osteotomy. It has been reported that severe resection of the lateral tibial condyle caused by excessive valgus osteotomy can affect implant fixation and lead to subsidence in the longterm ${ }^{14-16)}$. However, these complications were not observed in our patients, who underwent more valgus osteotomy; tibial component subsidence was observed in a single case in which the center of the intercondylar eminence was used as a reference for tibial osteotomy. In the meantime, movements of a cutting guide, differences between intramedullary and extramedullary alignment jigs ${ }^{17)}$ and between open and slotted cutting guides can also affect treatment results ${ }^{18,19)}$. Recently, navigationassisted TKA and robot-assisted TKA designed to reduce errors of tibial osteotomy and obtain correct alignment have been introduced and addressed in many studies. Favorable results were documented in the studies carried out by Bellemans et al. ${ }^{20)}$ using Robodoc and Mizu-Uchi et al. ${ }^{21)}$ using a computed tomographybased navigation system. However, Won et al. ${ }^{22)}$ reported that the incidence of outliers was $6 \%$ in their study of TKA using an electromagnetic navigation. Bae et al. ${ }^{23)}$ suggested the need to be cautious with navigation-assisted TKA in knees with varus deformity based on their observation that the postoperative mechanical axis was more significantly varus in patients with $20^{\circ}-30^{\circ}$ of preoperative varus deformity than those with $10^{\circ}-20^{\circ}$ of preoperative varus deformity. In addition, navigation-assisted TKA is an expensive surgery. Therefore, it is our understanding that our method that requires a slight modification of the conventional methods would be more helpful in obtaining stability and correct tibial component alignment in patients with severe varus deformity.

The limitations of the present study include: 1) the number of cases was small and even some of them were not available for follow-up, which might have affected the study results; 2) the possibility of lateral subsidence of tibial component in patients with the lateral eminence used as a reference for tibial osteotomy has yet to be assessed in the long-term follow-up; and 3) additional comparative studies using intramedullary alignment jigs or navigation-assisted techniques were not conducted.

\section{Conclusions}

At 6 years after total knee arthroplasty, the tibial component alignment was within the acceptable range in both, group I (the center of the intercondylar eminence was used as a reference for tibial osteotomy) and group II (lateral eminence was used as a reference for tibial osteotomy). Although no statistically significant difference was observed, tibial osteotomy was more varus and the incidence of outliers $\left(>3^{\circ}\right.$ in either varus or valgus) was lower in group II. The results of our study need to be confirmed through further studies including a larger sample size and long-term follow-up.

\section{References}

1. Ritter MA, Faris PM, Keating EM, Meding JB. Postoperative alignment of total knee replacement. Its effect on survival. Clin Orthop Relat Res. 1994;(299):153-6.

2. Windsor RE, Scuderi GR, Moran MC, Insall JN. Mechanisms of failure of the femoral and tibial components in total knee arthroplasty. Clin Orthop Relat Res. 1989;(248):15-9.

3. Han HS, Cho YJ, Yoon KS, Lee JH, Lee JH, Jo HC, Kang SB. Accuracy of intramedullary versus extramedullary tibial alignment guides: a randomized, prospective study in bilateral total knee arthroplasty. J Korean Knee Soc. 2007;19:181-6.

4. Cho WS. Arthroplasty of the knee joint. Seoul: Young Chang; 2004. p266-315.

5. Nam WD, Rhyu KH, Han KY. The change of proximal reference of tibial plateau in total knee replacement: the cadaveric study. J Korean Knee Soc. 2005;17:69-72. 
6. Hsu HP, Garg A, Walker PS, Spector M, Ewald FC. Effect of knee component alignment on tibial load distribution with clinical correlation. Clin Orthop Relat Res. 1989;(248):13544.

7. Teter KE, Bregman D, Colwell CW Jr. Accuracy of intramedullary versus extramedullary tibial alignment cutting systems in total knee arthroplasty. Clin Orthop Relat Res. 1995;(321):106-10.

8. Engh GA. The difficult knee: severe varus and valgus. Clin Orthop Relat Res. 2003;(416):58-63.

9. Tew M, Waugh W. Tibiofemoral alignment and the results of knee replacement. J Bone Joint Surg Br. 1985;67:551-6.

10. Lotke PA, Ecker ML. Influence of positioning of prosthesis in total knee replacement. J Bone Joint Surg Am. 1977;59:779.

11. Teeny SM, Krackow KA, Hungerford DS, Jones M. Primary total knee arthroplasty in patients with severe varus deformity. A comparative study. Clin Orthop Relat Res. 1991;(273):19-31.

12. D'Lima DD, Chen PC, Colwell CW Jr. Polyethylene contact stresses, articular congruity, and knee alignment. Clin Orthop Relat Res. 2001;(392):232-8.

13. Green GV, Berend KR, Berend ME, Glisson RR, Vail TP. The effects of varus tibial alignment on proximal tibial surface strain in total knee arthroplasty: The posteromedial hot spot. J Arthroplasty. 2002;17:1033-9.

14. Hofmann AA, Bachus KN, Wyatt RW. Effect of the tibial cut on subsidence following total knee arthroplasty. Clin Orthop Relat Res. 1991;(269):63-9.

15. Matsuda S, Mizu-uchi H, Miura H, Nagamine R, Urabe $\mathrm{K}$, Iwamoto Y. Tibial shaft axis does not always serve as a correct coronal landmark in total knee arthroplasty for varus knees. J Arthroplasty. 2003;18:56-62.

16. Matsuda S, Tanner MG, White SE, Whiteside LA. Evaluation of tibial component fixation in specimens retrieved at autopsy. Clin Orthop Relat Res. 1999;(363):249-57.

17. Brys DA, Lombardi AV Jr, Mallory TH, Vaughn BK. A comparison of intramedullary and extramedullary alignment systems for tibial component placement in total knee arthroplasty. Clin Orthop Relat Res. 1991;(263):175-9.

18. Laskin RS. Instrumentation pitfalls: you just can't go on autopilot! J Arthroplasty. 2003;18:18-22.

19. Plaskos C, Hodgson AJ, Inkpen K, McGraw RW. Bone cutting errors in total knee arthroplasty. J Arthroplasty. 2002;17:698-705.

20. Bellemans J, Vandenneucker H, Vanlauwe J. Robot-assisted total knee arthroplasty. Clin Orthop Relat Res. 2007;464:1116.

21. Mizu-Uchi H, Matsuda S, Miura H, Higaki H, Okazaki $\mathrm{K}$, Iwamoto Y. Three-dimensional analysis of computed tomography-based navigation system for total knee arthroplasty: the accuracy of computed tomography-based navigation system. J Arthroplasty. 2009;24:1103-10.

22. Won YY, Cui WQ, Lee DH, Piao TH, Hur JH, Shin DS. Comparison of the radiologic results of total knee arthroplasty using electromagnetic navigation with the conventional technique. J Korean Orthop Assoc. 2008;43:760-5.

23. Bae DK, Yoon KH, Song SJ, Kim SG, Im YJ, Kim MH. Comparative analysis of radiologic measurement according to TKR using computer assisted surgery and conventional TKR. J Korean Orthop Assoc. 2005;40:398-402. 